\title{
建设项目工程造价风险管理中 BIM 技术的应用
}

\section{Discussion on BIM Technology in Risk Management of Construction Project Cost}

\author{
张尚基 \\ Shangji Zhang \\ 广东理工学院 中国・广东 肇庆 526100 \\ Guang Dong Polytechnic College, Zhaoqing, Guangdong, 526100, China
}

\begin{abstract}
摘 要: 在建设项目工程造价风险管理系统中应用 BIM 技术能够有效提炼 BIM 技术的价值, 使 BIM 技术的作用得到全面 的发挥。论文主要围绕 BIM 技术在建设项目工程造价风险管理中的具体运用方式,阐述在风险识别阶段应用 BIM 技术的优 点, 通过应用 BIM 技术提高建设项目工程造价风险管理的水平。
\end{abstract}

\begin{abstract}
The application of BIM Technology in construction project cost risk management system can effectively extract the value of BIM Technology, and make the role of BIM Technology fully play. This paper mainly focuses on the specific application of BIM Technology in construction project cost risk management, expounds the advantages of applying BIM Technology in risk identification stage, and improves the level of construction project cost risk management by applying BIM Technology.
\end{abstract}

关键词: 建设项目; 工程造价; 凤险管理; BIM 技术

Keywords : construction project; project cost; risk management; BIM Technology

DOI : $10.36012 /$ etr.v2i7.2220

\section{BIM 技术概述}

BIM 是一种建筑设计模型, 其基础是与建筑工程项目设 计有关的信息技术,而在这些信息技术之上建立三维建筑模 型, 就是对 BIM 技术的有效应用。BIM 技术可以应用于建设、 管理领域, 能够提高建设、管理领域的工作质量和效率, 也能 够通过模拟呈现建筑物的各项数据。

BIM 有四个特点, 分别是一体化性、协调优化性、模拟性 和可视化, BIM 技术的可视化指 BIM 技术能够使与建筑相关 的各项数据都通过三维模型的方式展现出来, 使建筑设计图 更加立体, 虽然只是虚拟的图像展现, 但是也能够使设计人 员和施工人员更加直观地看到建筑设计中的各种情况, 有利 于提高建筑设计和建筑施工的质量和效率。建筑项目的施工 生命周期非常漫长，应用 BIM 技术能够使其整合为一个动 态数字模型, 而由 BIM 技术制作的动态数字模型中包括建 筑项目的全部信息 ${ }^{[1]}$ 。BIM 技术的协调优化性则是指想要应
用 BIM 技术, 就必须要收集更多的数据, 并对这些数据进行 科学处理, 只有立足于数据基础之上, 才能够构建数字信息 模型。而如果对这些数据信息进行共享, 就能够构建虚拟的 建筑项目, 在这个虚拟的项目上能够呈现出施工的各个环节 中的各项数据信息, 只需要通过 BIM 技术就能够实现各方 协同作业, 使建筑工程项目得到更好的开展。而 BIM 技术的 模拟性并不是指 BIM 技术对建筑模型的模拟, 而是在 BIM 技术模拟建筑模型的同时, 也能够对模拟出的建筑模型进行 操作模拟, 利用操作模拟预测建设工程施工中可能出现的问 题, 并根据预测的过程制定相应的方案, 尽可能降低或避免 建设工程造价风险。

\section{2 建设项目造价风险管理研究}

\section{1 建设项目造价风险管理概述}

风险管理本身有其标准的流程,通过标准的流程对建设 项目进行风险管理, 能够系统性地对建设项目中所存在的风 
险进行识别和评估, 提炼出其中所存在的风险, 提前做好应 对措施, 让风险能够在可掌控的范围内 ${ }^{[2]}$, 如果不能够及时发 现建设项目中的工程造价风险, 甚至任由风险进一步扩大, 就很有可能会给建设项目带来不可挽回的损失。工程造价管 理本身就是要对建设项目工程造价进行控制, 所以必须要对 其建设项目施工过程中的各项数据信息进行掌握和处理,使 建设项目各个阶段的风险性都能够得到控制, 而风险性造价 主要就是由建设项目风险所引起的, 也是建设项目风险的主 要体现, 因此, 在对建设项目进行造价风险管理时也需要考 虑到这一方面。

\section{2 建设项目各阶段的造价风险管理应用}

在建设项目的各个阶段都会存在一定的风险性,而对建 设项目进行造价风险管理就必须要针对其风险性进行控制、 评估和应对, 避免风险进一步扩大, 减少其工程造价可能会 给建设企业带来的损失。在设计阶段有可能出现设计方案或 设计单位招投标存在一定的风险,这一阶段所出现的风险会 对工程造价造成非常大的影响, 想要应对这一风险, 就必须 要签订正规的合同,依法规范设计投标,制定明确、合理的工 程造价管理方案。施工阶段如果出现工程设计的变更、建设 单位投资变动和工期的变动, 都会对建设工程造成一定的影 响，虽然其影响没有设计阶段所带来的工程造价风险影响 大, 但是, 如果不能很好地控制施工阶段的建设项目的工程 造价风险, 也会使建设企业损失惨重, 而想要应对这一风险, 就必须要严格遵守合同的条约,严格把控工程款的支付。在 竣工验收阶段,如果施工单位出现错误计算或是建设单位对 市场错误把控, 也很有可能会给建设工程带来一定的风险, 而这一阶段已经是造价风险管理的最后一个阶段, 如果能够 在最后一个阶段把好关, 就能够使建筑工程完美竣工, 想要 避免这种风险的产生, 也必须要做好评估工作, 安排专业人 员对建设工程进行评估。

\section{BIM 在建设项目造价风险管理中的应用研究}

\subsection{BIM 技术在风险造价管理中的应用优势}

BIM 技术是一项新型信息技术，利用 BIM 技术能够打 造出一个有效的建设项目公用平台, 有利于建设工程项目 中的各个单位之间的信息沟通和数据交流, 也就能够在一 定程度上降低建设项目的造价风险 ${ }^{[3]}$ 。如果能够将时间维度
引人到建设模型中, 就能够将模拟的施工数据和现实的施 工数据进行对比, 而这样的对比能够有效提升建设项目施 工的质量和效率。只是想要在建设模型中引入时间维度, 就 必须要利用 BIM 技术, BIM 技术能够有效帮助建设施工项 目发现自身的问题, 并及时调整建设项目的设计方案, 有助 于建设单位深入了解施工的情况, 对施工的进度和施工的 方案进行调整。除此之外, 也有利于监理单位对建设工程项 目进行监督和管理, 而 BIM 技术不仅能够模拟建筑模型, 同 时也能够对整个建设工程项目施工环节中的数据进行处理。

\subsection{BIM 技术在项目各阶段造价风险管理中的应用}

在建设项目中应用 BIM 技术必然会给建设项目带来一 定的影响, 而影响最大的就是造价风险管理这一部分, 因为 建设项目的造价风险管理几乎完全依赖于 BIM 技术, 如果 能够有效利用 BIM 技术, 自然就能够提升建设项目的造价 风险管理的水平, 而在设计阶段 BIM 技术的应用能够将设 计的图纸转化为建筑模型, 并且能够帮助设计师减少制图的 时间和返工的次数, 提升设计的质量和效率, 避免由于前期 的设计问题而延误工期, 或给施工带来影响。而除此之外, BIM 技术也能够应用于竣工阶段, 能够快速有效地对建设项 目进行结算, 处理所收集到的建设项目相关资料信息, 并帮 助建设企业加快变更和索赔工作的进度, 提升利益各方的效 率,避免出现不必要的纠纷和损失。

\section{4 结语}

总而言之, BIM 技术在建筑行业中的有效性是母庸置疑 的,而信息技术的兴起与发展, 也推动着 BIM 技术在建设行 业中的发展。BIM 技术在在发达国家建设行业中的应用已经 非常普遍, 但在中国建设领域中还处于探索阶段, 有很多建 设企业还在观望 BIM 技术的应用情况。因此, 更加需要明确 BIM 技术给建设工程项目所带来的价值, 通过 BIM 技术推动 中国建设行业的发展。

\section{参考文献}

[1] 熊成岗.BIM 技术在工程造价管理中的应用[J].住宅与房地产, 2019(18):24.

[2] 周述志.BIM 技术在公路工程全过程造价风险管理中的应用 [J].城市建筑,2016(11): 177 .

[3] 朱习章.BIM 技术在工程造价管理中的应用探讨[J]. 低碳世界, 2018(8):313-314. 